\title{
THE TREATMENT OF LEPROSY
}

\author{
W. H. Jopling, M.R.C.P., M.R.C.P.(Edin.), D.T.M. \& H. \\ Senior Hospital Medical Officer, Hospital for Tropical Diseases, London, N.W.I
}

From whatever standpoint leprosy is viewed, whether from that of the clinician or the epidemiologist, the objective must be to diagnose and treat the maximum number of leprosy patients, not only because the disease is curable but because treatment renders 'open' cases non-contagious long before cure is obtained. Now that it is becoming generally accepted that the way to leprosy eradication lies through case-finding and treatment, an increasing responsibility falls upon doctors working in the tropics to undertake the treatment of leprosy in hospital or rural clinic out-patients, for facilities in leprosy hospitals (leprosaria) are far too limited to deal with the numbers of patients involved, and, in any case, admission to leprosaria should not be indiscriminate but should be restricted to cases where special social or medical indications exist. ${ }^{5}$ At present there are about 211,900 leprosy inpatients throughout the world, but seven times as many are receiving out-patient treatment, and on the estimated world incidence of 10-12 million leprosy sufferers, there are at least seven undiagnosed and untreated patients for every one under treatment. $^{5}$

It is apparent, therefore, that in countries where leprosy is highly endemic, doctors without previous special training are likely to be called upon to shoulder the responsibility of treating leprosy out-patients, making use of the services of a leprosy specialist when difficulties arise, and it is for doctors such as these that this paper has been written.

\section{Chemotherapy. (I) Drugs which can be Recommended}

(I) The Sulphones. The sulphone group of drugs hold pride of place in treatment and possess two important advantages over other anti-leprosy drugs: first, they are much cheaper, and, secondly, leprosy bacilli have not been known to develop sulphone resistance. Before describing the sulphones in common use, I would like to make some general remarks which apply to them all: (I) There is little to choose between them for effectiveness. (2) They have certain side-effects in common (see below). (3) Dosage should $\vec{b}$ built up gradually, taking 4-5 months to reach the maximum, particularly in dimorphous (bog derline) and lepromatous cases because of their tendency to develop reactional states which maj. damage important structures such as periphersy nerves, but there is good evidence that in tube it culoid leprosy maximal doses can be given from the beginning. ${ }^{18}$ (4) Sulphones act bacterios statically and the minimum effective dose for each compound is not known. Speaking generally, it is my belief that patients are given larger doses than they need, and the most important lesson if the treatment of leprosy is that it is better to giv too little sulphone than too much. (5) Care mus be taken not to increase the dose if there are signs of reaction (see below). (6) Some clinicians their patients rest periods from sulphone, sucla two weeks' rest every three months, but otlese have not observed any ill-effects from giving the drug continuously. (7) Regarding the length of treatment, the Inter-Regional Leprosy Conferencos at Tokyo in 1958 recommended that tuberculoi⿺

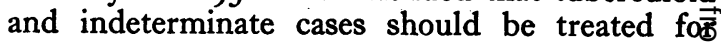
two years, or until all signs of activity have ceased for 18 months, whichever is longer; treatment of lepromatous and dimorphous cases should go on for at least two years after all signs of activitg have ceased. ${ }^{5}$ An alternative scheme would be tôे carry out a lepromin test when the disease has become inactive, and I would recommend treating patients with a positive test for 18 months afte? this, and patients with a negative test for as long as possible on half the maximal dose. This should radically reduce the incidence of relapses of lepros matous leprosy years after apparent cure.

(a) Dapsone. The most widely used sulphong at the present time is dapsone $\left(4: 4^{\prime}\right.$-diaminodiro phenyl sulphone); it is also known as DDSO DADPS, or the 'parent sulphone'. The B.P. preparation is put up in tablets of roo mg., but the I.C.I. product (tab. Avlosulfon) is put up it tablets of $50 \mathrm{mg}$. and $100 \mathrm{mg}$. The commencins dose is $25 \mathrm{mg}$. twice a week, increasing slowly over the next 4-5 months to $350 \mathrm{mg}$. twice a week at this stage 100 $\mathrm{mg}$. can be given daily if mor 
convenient, especially to out-patients who find it easier to remember to take treatment daily than at longer intervals. In either case the tablets are taken in a single dose. The maximal dosage of $700 \mathrm{mg}$./week will prove suitable for most adult patients in the tropics, but where heavier patients are being treated, or where it is desired to correlate dosage with body weight (as in children), the maximum dosage can be calculated as $14 \mathrm{mg}$. $/ \mathrm{kg}$. week or $2 \mathrm{mg}$. $/ \mathrm{kg}$./day.

Under certain conditions it may be preferable to treat on a fortnightly basis, and various longacting preparations are being tried. One is a suspension of dapsone in arachis oil to which aluminium stearate has been added; another is a suspension in equal parts of chaulmoogra oil and ethyl esters of chaulmoogra. ${ }^{17}$ Such 'depot' preparations contain $1.2 \mathrm{~g}$. of dapsone in $5 \mathrm{ml}$. of oil, and one injection of $5 \mathrm{ml}$. is given intramuscularly every fortnight. Oily injections are inclined to be painful, however, and may give rise to abscesses, and it is clear that the ideal preparation has yet to be found. In this respect it has recently been observed that 'Avlosulfon' Soluble (see below) injected fortnightly gives results on a par with those obtained from oral DDS given twice weekly or from long-acting oily preparations. ${ }^{8}$

(b) 'Avlosulfon' Soluble. I.C.I. chemists have overcome the problem of dapsone's insolubility in water by preparing an aqueous solution of a disubstituted derivative of DDS which breaks down in the body to liberate half its weight of dapsone, i.e. I ml. of 'Avlosulfon' Soluble= $200 \mathrm{mg}$. of dapsone. It is put up in rubber-capped bottles containing $50 \mathrm{ml}$. and dosage is $0.25 \mathrm{ml}$. intramuscularly twice weekly, increasing by 0.25 ml. every fortnight and remaining on the maximal dose of 2-3 ml. twice weekly.

(c) Solapsone (Sulphetrone, Burroughs Wellcome). Solapsone is a disubstituted derivative of DDS which, taken orally, is hydrolyzed in the stomach to DDS. When g:ven by intramuscular injection, however, it does not break down to DDS and its anti-leprosy activity is due to semi-solapsone. This is a monosubstituted derivative of DDS and is derived partly from semi-solapsone present in commercial solapsone and partly from chemical breakdown in the body. ${ }^{4}$ It is.put up as a $50 \%$ aqueous solution, each millilitre containing $0.5 \mathrm{~g}$. solapsone, and the dosage is $0.5 \mathrm{ml}$. intramuscularly twice a week, increasing by $0.5 \mathrm{ml}$. every fortnight to a maximum of $3 \mathrm{ml}$. (I.5 g. solapsone) twice a week and continuing at this level.

\section{Toxic Effects of Sulphone}

These are rare in the dosage outlined above, and the one most frequently encountered is haemolytic anaemia. Attention has been drawn to the presence of Heinz bodies in the blood as an indication of impending haemolysis. ${ }^{22}$ One single case of agranulocytosis has been recorded. ${ }^{19}$ Other toxic effects include methaemoglobinaemia, hepatitis and dermatitis. Psychosis is usually listed as a toxic effect, but caution must be observed in accepting this as there are many possible factors accounting for the high incidence of psychosis in in-patients in leprosaria, chief of which are the emotional stresses and strains associated with segregation. It has not been shown that out-patients taking sulphone are prone to psychosis, and it is significant that patients who recover from a psychotic illness are often able to resume sulphone therapy.

A recent report from the Belgian Congo describes black or dark brown macules developing during dapsone therapy and gradually disappearing on withdrawal of the drug. ${ }^{3}$

(2) Thiambutosine. This is the Approved Name for the diphenyl thiourea compound marketed under the name Ciba 1906 and previously called DPT, thiocarbanile or S.U.rgo6. Like sulphone, its action in leprosy is bacteriostatic. In the early stages of treatment it gives results which are better than those from sulphone and without any toxic effects, ${ }^{10}$ but there is a likelihood of drug resistance developing after about three years and, for this reason, sulphone should be added by the end of the second year of treatment and Ciba I906 can be withdrawn by the end of the third year. Theoretically there is a risk of a thiouracil-like effect on the thyroid gland, but in practice this has not proved important. Dosage: $500 \mathrm{mg}$. (one tablet) daily for two weeks, increasing the daily dose by $500 \mathrm{mg}$. at fortnightly intervals to a maximum of 2-3 g. daily (4-6 tablets). For children the maximum daily dose can be calculated as $40 \mathrm{mg} . / \mathrm{kg}$. of body-weight. Maximal absorption occurs after a single dose of $\mathrm{I} .5 \mathrm{~g} .{ }^{12}$ therefore any daily dosage larger than this must be divided. One of the chief advantages of Ciba 1906 is that it is less likely than dapsone to precipitate reactions, and it is particularly useful in dimorphous leprosy complicated by neuritis.

\section{Chemotherapy. (2) Potentially Useful Drugs Undergoing Trials}

(I) Ditophal. This is the Approved Name of diethyl dithiolisophthalate, a compound manufactured by I.C.I. under the name Etisul (previously called Etip). It is put up as a cream for inunction and its anti-leprosy action is due to the release of ethyl mercaptan in the body after absorption through the skin. Unlike standard anti-leprosy drugs, ethyl mercaptan appears to act bactericidally, and there is rapid improvement at first. ${ }^{9}$ Davey has found that bacilli become 
resistant to Etisul by the fourth month of treatment, and considers that it is best used in combination with DDS or Ciba 1906 for about three months and then stopped. ${ }^{10}$ Treatment should then be continued on standard lines.

(2) Vadrine (S. 13I). This oxdiazolone compound, manufactured by Geistlich in Switzerland, has been shown to be effective, ${ }^{15}$ but drug resistance tends to develop after about a year. It is now being tried in combination with dapsone, and results are encouraging.

(3) Cycloserine. The literature on this antibiotic is in French, and the first report appeared in $1957 .^{-1}$ Although it appears to be effective in leprosy, expense and side effects will probably preclude its general use.

(4) Methimazole. This compound, I-methyl-2mercaptoimidazole, introduced in 1949 for the treatment of thyrotoxicosis, ${ }^{23}$ has an antithyroid activity much greater than that of thiouracil. There are indications that it is a very potent antileprosy drug, and its use in leprosy is being studied in Central America.

\section{Complications of Leprosy and their Manage- ment}

Reactional States. A proportion of patients undergo reactional states (reactions) during treatment, and, to understand how to treat them, it is necessary to clarify this very confused subject. ${ }^{16}$ From the clinical standpoint there are two basic types of reaction. The first ('Type I') occurs in any form of leprosy and is characterised by swelling and redness of existing leprosy lesions, with or without neuritis. The second ('Type 2 ') is quite distinct as it occurs only in lepromatous leprosy and existing leprosy lesions remain unchanged. It is known as erythema nodosum leprosum because of the crops of erythematous nodes and patches which may appear on the skin; other manifestations are fever, neuritis, arthralgia, bone pains, orchitis, irido-cyclitis, anaemia and mental depression.

There is no specific treatment for 'Type I' reaction. If skin smears at the onset of the reaction contain an increased number of bacilli it would be reasonable to continue anti-leprosy treatment, but the drug could be stopped if bacilli were fewer or absent. In either case, the drug should be stopped immediately if muscle paralysis is threatened and, if possible, the patient should be admitted to hospital. Muscle weakness or paralysis requires suitable splinting and physiotherapy, and an injection can be given into the affected motor nerve: just above the elbow for the ulnar nerve, in the carpal tunnel for the median nerve, and at the neck of the fibula for the common peroneal nerve. A useful formula for the injection is hyalase 1500 units dissolve in $\mathrm{I} \mathrm{ml}$. of $2 \%$ procaine solution and mixed wit I $\mathrm{ml}$. of hydrocortisone suspension containin $25 \mathrm{mg}$. $/ \mathrm{ml}$., and a size 14 needle is ideal. This type of injection can be repeated if nerve function shows signs of improving; if improvement does not occur, systemic steroid therapy can be trieg but its value has not been established.

'Type 2 ' reaction is much more responsive to treatment. Although no special treatment $\mathbb{\mathbb { R }}$ required, apart from reducing the dose of tho anti-leprosy drug, if the reaction is mild, further steps will be necessary if there is fever and systemic disturbance. In this event the drug must b $\vec{E}$ stopped and the effect of antimony can be trief This is conveniently given in the form of 9 daily intramuscular injection of $2 \mathrm{ml}$. of St? bophen, but antimony can be discontinued aftes a week if no improvement occurs and an orat antimalarial such as chloroquine can be tried. Steroid therapy ${ }^{14}$ can be instituted if thes measures fail, and the effect is dramatic, buff steroids should not be used without adequate reason or without knowledge of their side effects Two tablets of cortisone (50 mg.) are given eights hourly on the first day, reducing by $12.5 \mathrm{mg}$. of $25 \mathrm{mg}$. each day so long as the reaction is being controlled; in this way a short course of $501 \overline{8}$ days may suffice, and the anti-leprosy drug eap be resumed cautiously. Cortisone's tendencyōte cause electrolyte disturbance is countered by ducing salt intake and by taking potassium by mouth in the form of Mist. Pot. Cit. (B.P.C.) $\frac{1}{2}-\frac{Q}{9}$ fl. oz. daily. If a short course does not contro the reaction it may be necessary to continue steroid at the lowest effective level, but in such $\overrightarrow{\vec{a}}$ case it would be desirable to change to one of cortisone's analogues such as prednisone or dexamethasone as these cause minimal electrolyte disturbance. If prednisone is selected it woule्ge be preferable to give it in an enteric-coated form to reduce the risk of gastric disturbance. ${ }^{25} \mathrm{Re} 3$ lative dosages can be calculated on the basis that prednisone is five times more powerful than cortisone and dexamethasone is thirty times more potent. Anti-leprosy treatment is given con? currently.

If irido-cyclitis is the principal manifestation of a ' Type 2 ' reaction, systemic steroid may bస avoided by instilling $\mathrm{r} \%$ cortisone eye-dropses

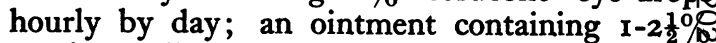
can be applied at night. Atropine drops must be instilled twice daily to keep the pupil dilated. Similarly, if peripheral nerves are bearing the brunt of the reaction, intraneural injections cat be given with very good effect in place of systemic steroids.

Paralysed Muscles. Paralysis of recent origiñ 
calls for splinting on the orthopaedic principle that a paralyzed muscle must be supported, and this is combined with physiotherapy. ${ }^{24}$ Surgical treatment is required for permanent paralysis; this may take the form of a fascial graft to correct facial palsy, a tendon graft to correct claw hand, or a tendon transfer for foot-drop. This important subject has been developed in a number of recent papers. $^{2}, 7,11,13$

Anaesthetic Hands or Feet. The danger lies in damage to skin and bone resulting from repeated (and avoidable) trauma, and the doctor has the important task of advising how damage can be prevented; it may mean a change of occupation, the wearing of gloves at work or when cooking, using a cigarette holder when smoking, or being supplied with suitable footwear. ${ }^{20}$ Once a trophic ulcer of the foot has developed it must be healed by rest in bed or by a below-knee walking plaster retained for 4-6 weeks; after this it will be necessary to supply suitable footwear and to advise travelling by bicycle rather than on foot.

Burns and other hand injuries should be splinted until healed, otherwise the patient, feeling no pain, will continue to use the injured member. It is important, too, that the patient should learn to inspect his hands and feet daily so that splinters and minor injuries can receive early treatment. Neglected trophic ulcers lead to osteomyelitis and eventual amputation of digits.

Facial Disfigurement. Plastic surgery can play a very important part in the rehabilitation of the leprosy patient, especially in the provision of eyebrows and in the correcting of facial disfigurement caused by saddle-nose, ectropion, pendulous ear-lobes, and by excessive folds of skin.

\section{REFERENCES}

I. BEISSEGE, H., CHAMBON, L., and NGUYEN-VAN-AI (1957), Bull. Soc. méd. Hóp. Paris, 25/26, 807.

2. BRAND, P. W. (1958), $\mathcal{~}$. Bone $f t$ Surg. (Brit. ed.), 40, 618 .

3. BROWNE, S. G. (1959), Trans. roy. Soc. trop. Med. Hyg., 53, 495.

4. BUSHBY, S. R. M., and WOIWOOD, A. J. (1955), Amer. Rev. Tuberc., 72, 123.

5. Chron. Wld Hlth Org. (1960), 14, 3.

6. COCHRANE, R. G. (1959), 'Leprosy in Theory and Practice'. Bristol: John Wright.

7. COOK, J. (1959), E. Afr. med. F., 36, 4 IO.

8. CURRIE, G. (1959), Leprosy Rev., 30, 220.

9. DAVEY, T. F. (1959), Ibid., 30, 141 .

I0. DAVEY, T. F. (1960), Trans. roy. Soc. trop. Med. Hyg., 54, 199.

Ir. DREISBACH, J. A. (1959), W. Afr. med. F., 8, 308.

12. ELLARD, G. A. (1960), Leprosy Rev., 31, 53.

13. FRITSCHI, E. P., and BRAND, P. W. (1957), Int. f. Leprosy, 25, 1 .

14. JOPLING, W. H., and COCHRANE, R. G. (1957), Leprosy Rev., 28, 5.

15. JOPLING, W. H., and RIDLEY, D. S. (1958), Ibid., 29, 143.

16. JOPLING, W. H. (1959), Ibid., 30, 194.

17. LAURET, L., LAVIRON, P., KERBASTARD, P., and JARDIN, C. (1956), Int. Э. Leprosy, 24, 138.

18. LEWIS, R. A., KYI-KYI, K., and EDWARDS, R. (1957), Ibid., 25, 370

19. MCKENNA, W. B., and CHALMERS, A. C. (1958), Brit. med. $\mathcal{F} ., \mathbf{i}, 324$.

20. PRICE, E. W. (1960), Leprosy Rev., 31, I59.

21. RAMANUJAM, K. (1960), Ibid., 31, 104.

22. SMITH, R. S., and ALEXANDER, S. (1959), Brit. med. $\mathcal{~ . , ~}$ i, 625 .

23. STANLEY, M. M., and ASTWOOD, E. B. (1949), Endocrinology, 44, 588.

24. THOMAS, R. E. (1954), Leprosy Rev.; 25, 16.

25. WEST, H. F. (1959), Brit. med. F., ii, 680. 